\title{
事业单位会计内部控制的优化措施
}

\author{
徐娜 \\ 烟台市园林建设养护中心 \\ DOI:10.12238/ej.v3i4.521
}

\begin{abstract}
[摘要] 在如今事业单位发展阶段,对于各部门工作的要求更为严格,特别对于财务管理部门的要求较 高,这事关事业单位的未来发展。因此,加强财务管理是必然的要求。为了达到这一目的, 就需要有关部 门能够提高财务管理的重视,与此同时,更应该加强会计内部控制与管理。一般而言,事业单位会计内部 控制方面会存在很多的问题,这不仅会影响工作的正常开展, 同样影响国家经济效益。对此, 有关单位需 要结合实际情况,采取一些积极有效的措施,真正加强会计内部控制。本文就其中的问题以及优化措施进 行简要分析。
\end{abstract}

[关键词] 事业单位; 会计; 内部控制; 优化

中图分类号：F23 文献标识码：A

会计内部控制指的是单位为了提高 会计信息品质, 保护资产安全以及完整, 保证有关法律条文以及规章制度的落实 等, 拟定和施行的控制措施和程序。长期 以来, 事业单位经济业务核查计算方法 比较单一, 人们的会计内部控制意识有 所欠缺, 执行力也不够, 致使在一定程度 上导致会计信息失真, 无法精确反馈财 务收入支出的问题。因此, 要加强对事业 单位会计内部控制的探究, 针对出现的 问题提出有效的优化措施。

1 事业单位会计内部控制工作 中存在的问题

1. 1缺乏科学的风险评估机制

在事业单位的运营发展过程中, 可 能存在着或多或少的风险。这些风险因 素的存在, 不仅影响着事业单位的发展, 更制约着它服务职能的有效发挥。事业 单位为提升发展质量, 不断优化自身的 核心竞争力, 必须注重风险管控, 必须注 重风险管理, 以便更好的提升自身的风 险应对能力。但现阶段, 事业单位在会计 内部控制过程中, 明显缺乏科学的风险 评估机制, 这就很难真正做到风险防范 以及风险控制, 也很难优化风险应对质 量。一方面, 事业单位会计人员在工作实 践中, 可能将工作重心放在了财务处理 方面, 并没有风险防范以及风险预警的
意识和概念, 这就在很大程度上影响着 风险防控的整体水平与质量。另一方面, 在事业单位的运营发展过程中, 财务会 计人员在对风险进行管理与控制的过程 中, 更加强调事后控制, 缺乏科学的事前 防范意识, 缺乏科学的事前防范体系, 这 在很大程度上影响着事业单位的长效可 持续发展。此外, 虽然事业单位在运营发 展过程中配备了一定量的风险防范人员, 但这些风险防范人员可能缺乏专业素养 的支撑, 无法真正理清风险, 也无法真正 做到风险预警以及风险防控。

\section{2 事业单位内部控制意识薄弱}

在事业单位的运营发展过程中, 整 体优化风险防控能力, 不断提升会计内 部控制工作的整体成效, 应该树立科学 的内部控制意识, 不断提升内部控制的 整体成效。但在实践过程中, 事业单位内 部控制意识相对比较薄弱, 无论是事业 单位的管理者, 还是事业单位财务管理 人员, 可能都缺乏系统全面的风险管理 以及风险认知, 比如部分事业单位的领 导干部虽然察觉到自身存在的风险, 但 没有落实相应的管理以及应对措施, 尤 其是没有充分践行科学的会计内控, 这 就使得风险因素越来越大。与此同时, 事业单位也没有健全会计内控制度, 这 使得会计内控工作极容易流于形式, 影
响着内部控制的整体成效。此外, 事业单 位管理人员也无法精准把握内部控制的 目标以及方向, 这些都影响着会计内部 控制的工作质量。

1.3 内部控制监督力度相对偏弱

优化会计内控工作, 需要依托于科 学的监督制度。事业单位若想科学提升 会计内部控制的整体水平, 应该匹配针 对性的内部控制监督管理体系, 不断夯 实监督力度, 不断提升监督质量。但在实 践过程中, 事业单位明显缺乏内部控制 的监督管理, 也没有构建科学的监督管 理体系, 这些都在很大程度上影响着监 督管理的整体成效。比如在事业单位会 计内部控制过程中, 缺乏科学的信息公 开机制, 这就使得很多关键的会计信息 得不到完整及时的披露, 这本身制约着 事业单位的内控管理成效以及运营成 效。与此同时, 事业单位缺乏必要的外部 监督机制。虽然事业单位也注重要求外 部监督机构来开展科学化的监督管理工 作, 但在实践过程中这种监督力度并不 大, 往往存在利益媾和的问题, 很难真正 提升监督管理的整体成效, 很难优化监 督管理的整体质量。

2 事业单位会计内部控制工作 的优化措施

2. 1建立健全风险评估机制 
事业单位应该着重加强风险防控, 依托于科学的风险评估工作, 综合性提 升风险预判与预警能力。在实践过程中, 事业单位应该构建科学的风险评估机制, 不断提升风险的研判以及预防控制能 力。在事业单位的运营发展过程中, 无论 是内部风险, 还是外部风险, 都可能影响 着事业单位的长效快速发展, 同时也制 约着事业单位的整体发展水平。因此, 事业单位必须充分构建科学的风险防范 体系, 加强对风险的评估以及管理等, 综 合性提升自身的风险应对以及风险防控 质量。一方面, 事业单位应该充分提升管 理人员的风险防控意识, 积极转变传统 的事后控制与管理的陈旧理念, 不断提 升风险防控的整体成效。事业单位还应 该着重调整事前、事中、事后控制比例, 把握事业单位会计内部控制工作的高效 性。另一方面, 事业单位在运营发展过程 中, 应该注重积极创新风险防控的手段 和方式, 不断创新风险防控工具和方法, 综合性提升风险防控以及评估工作的质 量。在信息技术全面快速发展的今天, 事业单位在内部控制工作过程中, 应该 着重构建信息化管理系统, 不断提升信 息化管理的整体成效, 积极依托于信息 技术来进行风险篮查、信息数据的高效 汇总以及会计信息的高效整合, 继而精 准计算与判断事业单位经营发展中可能 存在的诸多风险, 不断提升自身的风险 防范以及控制水平。与此同时, 事业单位 还应该充分结合自身的发展现状以及内 外部环境等, 科学构建风险评估机制。在 事业单位的运营发展过程中, 不同风险 的类型以及内容是存在明显的差异的, 不同风险的威胁以及危害也是不同的。 为提升风险防范能力, 为科学规避可能 存在的较大的风险, 事业单位必须构建
风险评估机制, 以科学的风险评估方式 以及标准来做好风险评估工作。

2.2 全面优化事业单位内部控制理 念和意识

在事业单位运营发展过程中, 整体 提升事业单位的运营发展水平, 不断提 升事业单位的综合竞争力, 应该全面开 展会计内部控制管理工作, 积极践行和 贯彻落实科学精准内控管理理念, 依托 于创新化的会计内控方法, 多措并举来 提升会计内控成效。当前, 事业单位领导 干部以及各个部门的管理人员明显缺乏 科学的会计内部控制管理意识, 这在很 大程度上影响和制约着事业单位的长效 快速发展。基于此, 事业单位应该不断创 新会计内部控制管理理念, 不断优化人 们的内部控制管理意识, 促使人们积极 依托于科学的会计内部控制管理来科学 开展工作。一方面, 事业单位在运营发展 过程中, 应该构建标准清晰的内部控制 管理机制, 充分明确不同人员的内部控 制管理任务以及管理目标, 不断提升内 部控制管理的整体成效。另一方面, 事业 单位还应该全面加强财务会计的教育管 理, 促使他们掌握科学的财务方面的知 识以及素养, 以更加专业的素养, 以更加 严谨的态度来面对会计内控工作。与此 同时, 事业单位全面强化工作人员的会 计内部控制管理意识, 不断优化他们的 思想, 不断提升他们的认知, 不断提升他 们的技能。

2. 3增强事业单位会计内部控制监 督质量

在事业单位的运营发展过程中, 科 学的会计内部控制扮演着关键性的角 色。整体优化事业单位的经营发展水平, 不断提升事业单位的核心竞争力, 事业 单位应该不断强化会计内部控制, 不断
提升会计内部控制的整体质量。为优化 会计内部控制的工作成效, 为提升会计 内部控制的管理质量, 应该辅之以完善 的会计内部控制监督机制, 综合性提升 监督管理的质量。一方面, 在事业单位运 营发展过程中, 应该强化资金的科学管 理与控制, 保障资金流向的合理性与科 学性, 同时避免资金的不合理浪费。另一 方面, 在事业单位会计内部控制过程中, 还应该全面优化审计工作, 不断提升审 计工作的质量, 不断优化审计工作的成 效。事业单位除必要时聘请外部机构来 进行审计外, 还应该成立专门性的审计 部门, 对事业单位各项财务活动进行综 合全面的审计, 及时发现会计内部控制 中存在的问题, 不断优化会计内部控制 的整体成效。

\section{3 结束语}

随着新《预算法》实施及事业单位 分类改革的推进, 我国事业单位为了适 应改革及不断提升会计信息质量的需要, 纷纷按照《事业单位内部控制制度规范》 要求建立、执行内控机制。就近几年事 业单位内控制度执行情况看, 多数事业 单位能够结合自身管理需要建立内控制 度, 并在事业单位内部有序开展, 内部控 制制度在规范会计核算、提高财务管理 效率及降低贪污舞弊风险、保证资产安 全等方面发挥着巨大的作用。

\section{[参考文献]}

[1]姜首丹.浅析事业单位人力资源 管理中的激励制度问题及对策 [J]. 建筑 发展,2017,1(2):160-161.

[2]刘立.浅议事业单位内部会计控 制存在的问题及改善措施 [J]. 经济 师,2017,(12):94+96.

[3] 昆永丽.行政事业单位会计内部控 制制度探索[J]. 时代经贸,2020,(9):65-66. 